\title{
Postmenopausal hormone therapy in the Brazilian Longitudinal Study of Adult Health (ELSA-Brasil): who still uses it?
}

\author{
Estela M. L. Aquino ${ }^{1 *}$, Maria-da-Conceição C. Almeida ${ }^{2}$, Greice M. S. Menezes ${ }^{1}$, \\ Roberta Carvalho de Figueiredo ${ }^{3}$, Isabela M. Bensenor ${ }^{4}$, Sotero Serrate Mengue ${ }^{5}$, \\ Maria de Jesus M. da Fonseca ${ }^{6}$ and Ligia Gabrielli ${ }^{1,7}$ \\ ${ }^{1}$ Instituto de Saúde Coletiva, Universidade Federal da Bahia, Salvador, Bahia, Brazil \\ ${ }^{2}$ Centro de Pesquisas Gonçalo Moniz, Fundação Oswaldo Cruz (Fiocruz), Salvador, Bahia, Brazil \\ ${ }^{3}$ Campus Centro Oeste Dona Lindu, Universidade Federal de São João Del-Rei, Divinópolis, Minas Gerais, Brazil \\ ${ }^{4}$ Faculdade de Medicina, Universidade de São Paulo, São Paulo, SP, Brazil \\ ${ }^{5}$ Programa de Pós-Graduação em Epidemiologia, Faculdade de Medicina, Universidade Federal do Rio Grande do Sul, Porto Alegre, Rio \\ Grande do Sul, Brazil \\ ${ }^{6}$ Escola Nacional de Saúde Pública, Fiocruz, Rio de Janeiro, RJ, Brazil \\ ${ }^{7}$ Centro de Diabetes e Endocrinologia do Estado da Bahia, Secretaria de Saúde do Estado da Bahia, Salvador, Bahia, Brazil
}

\begin{abstract}
Purpose We aim to investigate the patterns of hormone therapy (HT) use and associated factors in women participating in the Brazilian Longitudinal Study of Adult Health.

Methods This study included 3281 naturally menopausal women of 40 to 74 years of age at enrollment to the Brazilian Longitudinal Study of Adult Health study, who answered questions regarding their use and discontinuation of HT. Prevalence rates of current and previous HT use were calculated, and a multinomial logistic regression model was constructed to simultaneously analyze the associated factors.

Results The prevalence of HT use increased from 1995 onwards, peaking at $55.7 \%$ in 1997. A sharp decline occurred in the decade beginning in 2000, reaching $11.1 \%$ at the study baseline interview (2008-2010). Current use was associated with being $\geq 60$ years of age (Relative Risk Ratio (RRR): 1.81; 95\%CI: 1.10-2.96), divorced (RRR: 1.72; 95\%CI: 1.14-2.60), or married (RRR: 2.09; 95\%CI: 1.41-3.10); having a university education (RRR: 1.66; 95\%CI: 1.14-2.40) or postgraduate degree (RRR: 2.45; 95\%CI: 1.80-3.35); and having private health insurance (RRR: 2.86 ; 95\%CI: $2.00-4.09$ ). Body mass index $\geq 30 \mathrm{~kg} / \mathrm{m}^{2}$ was inversely associated with HT use (RRR: 0.37; 95\%CI: $0.26-0.53$ ) as was the presence of at least one contraindication to HT use (RRR: 0.63; 95\%CI: 0.44-0.89). Of the current users $\geq 60$ years of age, $79.1 \%$ had been using HT for at least 5 years, and $73.6 \%$ had been menopausal for at least 10 years.

Conclusion Although the use of HT has declined in Brazil, the women who continue using it are largely exceeding evidence-based limits of age, time since menopause, and time of use. Copyright (C) 2016 John Wiley \& Sons, Ltd.
\end{abstract}

KEY WORDS—-postmenopause; hormone therapy; inappropriate use; drug use; developing countries; pharmacoepidemiology;

Received 23 August 2015; Revised 26 January 2016; Accepted 08 February 2016

\section{INTRODUCTION}

During the final decades of the 20th century, it was widely believed that the benefits associated with the use of postmenopausal hormone therapy (HT) far

\footnotetext{
*Correspondence to: E. M. L. Aquino, Instituto de Saúde Coletiva, Universidade Federal da Bahia, Centro de Investigação ELSA-Brasil-UFBA, Rua Araújo Pinho, 513 Canela, 40110-150, Salvador, Bahia, Brazil. Email: estela@ufba.br

The authors hereby confirm that neither the manuscript nor any part of it has been published or is being considered for publication elsewhere.
}

exceeded the risks. This belief was based on results from observational studies pointing to a reduction in the risk of coronary disease and overall mortality in users of HT. Over that period of time, hormones were liberally prescribed to relieve menopausal symptoms and prevent cardiovascular disease and osteoporosis. It was estimated that in the USA at least six million women were in use of HT in $1992 .{ }^{1}$

In the early 1990s, several randomized clinical trials were conducted to investigate the effect of HT on the occurrence of cardiovascular disease. In 1997, a meta- 
analysis of over 50000 women identified an increased risk of breast cancer in HT users. ${ }^{2}$ In the following years, the results of the Heart and Estrogen/Progestin Replacement Study I and II were published, and the expected reduction in the rate of secondary cardiovascular events in women using HT compared with nonusers was not found. ${ }^{3,4}$ In 2002, the Women's Health Initiative (WHI), a large randomized clinical trial, compared nonhysterectomized women taking conjugated estrogens (EE) and medroxyprogesterone acetate and hysterectomized women taking EE alone with their respective controls. The WHI had to discontinue the group of women using $\mathrm{EE}+$ medroxyprogesterone acetate from the study because of the occurrence of an excessive number of cases of breast cancer and the ethical impossibility of justifying the prescription of HT after identification of those results. The same publication in which discontinuation of the study was announced also reported no reduction in cardiovascular events in the intervention group over a period of 5.7 years. ${ }^{5}$ In 2003, the first results of the Million Women Study, a retrospective observational study that evaluated around 1.1 million postmenopausal women in the UK, were released, showing an increased risk for breast cancer associated with the use of all types of HT. ${ }^{6}$

As a consequence of these publications, there was an inevitable decline in the prescription of HT in various parts of the world after 1998, coming to a head in $2002^{7-9}$ after the results of the WHI study. Limitations to the prescription of HT were recommended by various specialist societies ${ }^{10}$ and government health institutions. ${ }^{11}$ The same institutions have periodically reviewed those recommendations and have maintained the restrictions with respect to the indications for HT use. ${ }^{12,13}$ Current guidelines contraindicate the use for the prevention of chronic conditions, particularly cardiovascular disease. Its use is recommended in the case of premature ovarian failure and surgically menopausal women (bilateral oophorectomy prior to 50 years of age), although the need for studies to assess the cost-benefit ratio of this use has been strongly emphasized. HT is considered the most effective strategy for the treatment of the vasomotor symptoms associated with menopause, and indeed, the benefits seem to potentially outweigh the risks in women under 60 years of age or within 10 years of becoming menopausal. ${ }^{12,14}$ Despite the Food and Drug Administration's warning in 2003 recommending that the use of HT, when absolutely necessary, should be given at the lowest dose possible for the shortest time possible, ${ }^{13}$ in recent years, recommendations on the safety of use state that the dose and duration of use should be individualized and consistent with treatment goals. ${ }^{14}$

In Brazil, more than 10 years after dissemination of the information provided by those international studies, knowledge on HT use remains insufficient. Population-based studies conducted on this topic in Brazil were cross-sectional, with limited samples and selected populations. In addition, all were published in the first decade of the second millennium. ${ }^{15-20}$

The objective of this paper is to report on postmenopausal HT use patterns and their associated factors in women participating in the ELSA-Brasil project.

\section{METHODS}

\section{Study design and population}

This study evaluated data from the baseline examinations conducted for the ELSA-Brasil study, a multicenter research study including 15105 federal civil servants in six teaching and research institutions in the northeast, southeast, and south of Brazil. Further details regarding this study have been published elsewhere. ${ }^{21}$

For the present paper, the data of 3281 women who had gone through natural menopause were analyzed. These women were of 40 to 74 years of age at baseline and were enrolled to the ELSA-Brasil study between 2008 and 2010. Those with a history of premature ovarian failure, ${ }^{22}$ that is, primary and secondary amenorrhea due to radiotherapy, surgery, chemotherapy, or any condition resulting in menopause before age 40 years, for which the prescription is more liberal, were excluded. In the case of nine of the eligible women $(0.3 \%)$, the data available on their use of HT were incomplete, and they were removed from the analysis.

\section{Data collection}

Trained, certified personnel conducted face-to-face interviews using a structured questionnaire that contained a segment on women's reproductive history, including the points of interest dealt with in this article.

Menopausal status was assessed based on the women's answers to the following question: "Do you still menstruate?" (yes/no). For women answering "no," this was followed by another question asking how much time had elapsed since their last menstrual period (less than 6 months, between 6 months and 1 year, and more than a year). Information on age at menopause was obtained from the question "How old were you when you had your last 
menstrual period?" with the answer being recorded in years.

The use of HT was investigated from the women's answers to the question: 'Do you use or have you in the past used drugs containing female hormones (such as estrogen or progestin) to relieve menopausal symptoms, to prevent any disease such as osteoporosis or for any other reason?' (yes/no). It was emphasized that the drugs referred to in these questions were not those used for contraceptive purposes and included only those begun just before or after menopause. Those who responded positively were asked about their age at the time they began HT use, their age at the time of discontinuation (if applicable), the brand/generic name of the drug used (only current HT users), and the total time of use in years (all users).

Weight and height were measured using standard equipment and techniques. ${ }^{21}$

\section{Definitions and data analysis}

Natural menopause was defined in accordance with the World Health Organization's 1996 proposal $^{23}$ as the permanent cessation of menstruation resulting from the loss of ovarian follicular activity, retrospectively recognized after at least 12 consecutive months of amenorrhea for which there is no other obvious pathological or physiological cause.

Hormone regimens in use consisted of systemic estrogen, vaginal estrogen, estrogen + progesterone, tibolone, and other combinations including estrogen + testosterone and estrogen + tibolone.

Clinical contraindications to the use of HT included triglyceride levels $>500 \mathrm{mg} / \mathrm{dl}$, a medical history of congestive heart failure, acute myocardial infarction, stroke, thromboembolism, systemic lupus erythematosus, breast cancer, endometrial cancer, liver cirrhosis, and hepatitis.

Subjects were grouped according to their body mass index (BMI) as being of normal weight (BMI: 18-24), overweight (25-29), or obese ( $\geq 30$ ).

A time series was constructed of the annual prevalence of HT use (total and by having private health insurance) between 1995 and 2007, the interval for which complete data were available prior to baseline. Cases were defined as any postmenopausal women who had initiated HT use or were currently using HT in the year for which the calculation was being made. A linear regression analysis was performed, using the $R$-squared coefficient of determination to estimate the straight-line fit.

The prevalence rates of current and previous HT use were calculated according to age, marital status, race/skin color, education level, whether the woman had private health insurance, self-rated health (compared with people of the same age), BMI, and whether the woman had any clinical contraindications to the use of HT.

For the simultaneous analysis, a multinomial logistic regression model was constructed, and the relative risk ratios were defined for each parameter. The mlogitgof command was used to test the goodness of fit.

For the women who remained in use of systemic HT (users of vaginal estrogen alone being excluded), the proportional distribution was described by age group ( $\leq 59$ and $\geq 60$ years) according to the time elapsed since menopause, duration of use, and having at least one clinical contraindication to HT use.

All the statistical analyses were conducted using the Stata software program, version 13.0 (StataCorp, College Station, TX, USA).

\section{Ethical considerations}

All the subjects signed a written informed consent form. The internal review board of each participating institution and the Brazilian National Research Ethics Committee approved the study protocol.

\section{RESULTS}

According to the 3281 women who were between 40 and 74 years of age at baseline in the ELSA-Brasil study (2008-2010), had entered natural menopause, and had no history of premature ovarian failure, a sharp decline occurred in the use of HT over the first decade of the second millennium (Figure 1). At the beginning of this temporal series, more than half the women were in use of HT, with the prevalence rate reaching a peak $(55.7 \%)$ in 1997. After that, rates declined sharply throughout the decade, reaching a low of $27.4 \%$ in 2007 . This decline was less pronounced in women with private health insurance when compared with the group without health insurance.

At the interview conducted at the study baseline, current use already accounted for only $11.1 \%$ and was more common in the women who were older ( $\geq 50$ years of age), married, and white; had a better education level and private health insurance; described their health as very good or good; and had a BMI $<30$ and no clinical contraindications to HT use (Table 1).

Following simultaneous adjustment by multinomial logistic regression (Table 2), past use of HT was associated with being $\geq 60$ years of age at the time of the interview, being white or brown skinned, and having private health insurance. Continued use was associated with being $\geq 60$ years of age, being 


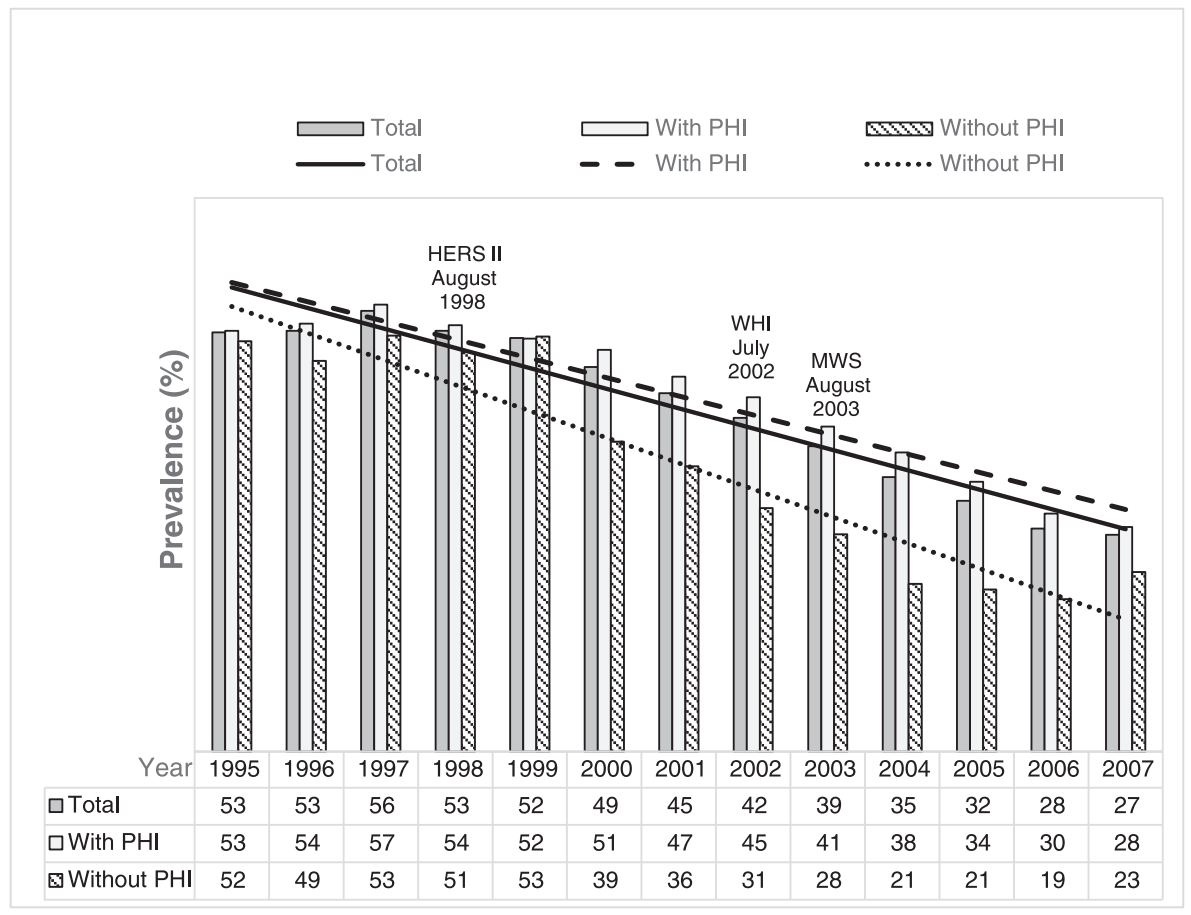

\begin{abstract}
PHI: private health insurance HERS II: The Heart and Estrogen / Progestin

Replacement Study II

WHI: Women's Health Initiative

MWS: The Million Women Study

a Excluding women with premature ovarian failure, i.e. primary and secondary amenorrhea due to radiotherapy, surgery, chemotherapy or any condition resulting in menopause before age 40 .
\end{abstract}

Figure 1. Annual trends from 1995 to 2007 in the prevalence of postmenopausal hormone therapy use in women who have undergone natural menopause (total and by having private health insurance). ${ }^{\mathrm{a} B r a z i l i a n}$ Longitudinal Study of Adult Health study

currently married or having been married previously, having a better education level (university or postgraduate degree), and having private health insurance. BMI $\geq 30$ and having at least one clinical contraindication to HT use were found to be factors associated with less use.

Hormone preparations consisting of a combination of estrogen and a progestin $(30.6 \%)$ and tibolone $(29.7 \%)$ were the most frequently used forms of HT. Only $16.2 \%$ of the respondents were currently using vaginal estrogen (data not shown). Excluding the latter and analyzing those in current use of systemic HT in greater detail (Table 3) revealed that the absolute majority of women $\geq 60$ years of age had been menopausal for at least 10 years $(73.6 \%)$ and had used HT for at least 5 years $(79.1 \%)$. In that age group, $15.2 \%$ of the women had at least one clinical contraindication to the use of HT; however, this proportion was not significantly different from that found for the women in the younger age group.

\section{DISCUSSION}

These baseline results from the ELSA-Brasil study confirm the trend observed in other countries regarding the discontinuation of HT use, ${ }^{1,7-9}$ particularly in the first decade of 2000 when the decrease in the prevalence exceeded $50 \%$. The initial levels were much higher than those reported in different countries in almost every continent. ${ }^{24}$

The finding that the use of HT was more common in the more educated women is consistent with the results of studies conducted in the $1990 \mathrm{~s},{ }^{25,26}$ which investigated poor compliance with treatment at a time when HT was being highly recommended, suggesting an effect of better access to health services. In the current scenario in which indications for use are more restricted, it is surprising that women in more privileged situations tend to continue using HT for prolonged periods, after reaching 60 years of age and after 10 years of menopause when the risks seem to 
Table 1. Pattern of hormone therapy use according to selected characteristics in women of 40-74 years of age at natural menopause. *Brazilian Longitudinal Study of Adult Health baseline study, 2008-2010

\begin{tabular}{|c|c|c|c|c|}
\hline Selected characteristics & $n$ & Never use $(\%)$ & Past use (\%) & Current use $(\%)$ \\
\hline Total & 3281 & 58.1 & 30.8 & 11.1 \\
\hline \multicolumn{5}{|l|}{ Age (years) } \\
\hline - 40-49 & 242 & 72.7 & 17.8 & 9.5 \\
\hline$\cdot 50-59$ & 1768 & 65.4 & 22.9 & 11.7 \\
\hline$\bullet \geq 60$ & 1271 & 45.2 & 44.3 & 10.6 \\
\hline \multicolumn{5}{|l|}{ Marital status } \\
\hline • Married & 1546 & 56.4 & 30.4 & 13.2 \\
\hline - Divorced/separated & 1250 & 58.3 & 31.9 & 9.8 \\
\hline - Single & 485 & 63.1 & 29.3 & 7.6 \\
\hline \multicolumn{5}{|l|}{ Race/skin color } \\
\hline - Black & 495 & 70.5 & 23.0 & 6.5 \\
\hline - Brown (mixed) & 805 & 60.2 & 31.2 & 8.6 \\
\hline - White & 1791 & 53.3 & 32.8 & 13.8 \\
\hline - Asian & 117 & 57.3 & 35.0 & 7.7 \\
\hline - Indigenous & 35 & 71.4 & 22.9 & 5.7 \\
\hline \multicolumn{5}{|l|}{ Education } \\
\hline - High school or less & 1556 & 65.7 & 28.5 & 5.8 \\
\hline - University education & 555 & 54.9 & 33.9 & 11.2 \\
\hline - Postgraduate degree & 1170 & 49.6 & 32.4 & 18.0 \\
\hline \multicolumn{5}{|l|}{ Private health insurance } \\
\hline • Yes & 2337 & 51.9 & 34.4 & 13.7 \\
\hline • No & 943 & 73.6 & 21.9 & 4.4 \\
\hline \multicolumn{5}{|l|}{ Self-rated health } \\
\hline • Very good/good & 2581 & 56.7 & 31.2 & 12.1 \\
\hline - Fair/poor/very poor & 700 & 63.3 & 29.6 & 7.1 \\
\hline \multicolumn{5}{|l|}{ BMI } \\
\hline$\cdot \leq 24$ & 1208 & 54.2 & 31.7 & 14.1 \\
\hline • 25-29 & 1226 & 53.9 & 34.1 & 12.0 \\
\hline$\bullet \geq 30$ & 847 & 69.8 & 24.8 & 5.4 \\
\hline \multicolumn{5}{|c|}{ Clinical contraindications to $\mathrm{HT}$ use $^{\dagger}$} \\
\hline$\bullet$ None & 2742 & 57.8 & 30.5 & 11.6 \\
\hline - At least one & 539 & 59.5 & 32.3 & 8.2 \\
\hline
\end{tabular}

BMI, body mass index; HT, hormone therapy.

*Excluding women with premature ovarian failure, that is, primary and secondary amenorrhea due to radiotherapy, surgery, chemotherapy, or any condition resulting in menopause before age 40 years.

${ }^{\dagger}$ Triglyceride levels $>500 \mathrm{mg} / \mathrm{dl}$ and medical history of congestive heart failure, acute myocardial infarction, stroke, thromboembolism, systemic lupus erythematosus, breast cancer, endometrial cancer, liver cirrhosis, and hepatitis.

outweigh the benefits. ${ }^{12-14}$ Studies conducted in Brazil $^{15-20,27-33}$ and in France ${ }^{34}$ confirmed this pattern in the early 2000 s.

The main limitation of this study is the lack of data on menopausal symptoms whose intensity could induce women to use HT despite being aware of the associated risks. In addition, there is no information on the occurrence of osteoporosis, which could contribute to the prescription of hormones for women with vasomotor symptoms. Furthermore, data were not collected on whether HT was prescribed by a physician or whether it was selfprescribed, and there was no information on whether women had attempted unsuccessfully to discontinue HT use. These factors should be the focus of further investigation.

The more frequent use of HT by women who have private health insurance and the less pronounced decline of HT use in this group merit further discussion. In Brazil, the public Unified
Health System (SUS) is based on the principles of universality and equity of access and comprehensiveness of care. ${ }^{35}$ However, about a quarter of the population has private health insurance, and segmentation of care does indeed exist because of socioeconomic reasons. ${ }^{35}$ In the SUS, the prescription and dispensing of drugs are regulated by the National List of Essential Medicines (RENAME); however, only conjugated estrogens (vaginal and oral) and medroxyprogesterone acetate are included in that list. ${ }^{36}$ Although state and municipal healthcare managers have the autonomy to buy other drugs based on regional needs, the drugs are not always available, ${ }^{37}$ which may contribute to the reduction in use in women who rely exclusively on the healthcare services of the SUS. As in other countries, the influence of the pharmaceutical industry on drug prescription, both in private settings and in public healthcare, must be considered. ${ }^{38-40}$ In Brazil, $64.2 \%$ of the physicians who are involved 
Table 2. Factors associated with past or current hormone therapy use by women of 40-74 years of age who had undergone natural menopause. *Brazilian Longitudinal Study of Adult Health baseline study, 2008-2010

\begin{tabular}{|c|c|c|c|c|}
\hline \multirow[b]{2}{*}{ Selected characteristics } & \multicolumn{2}{|c|}{ Past use } & \multicolumn{2}{|c|}{ Current use } \\
\hline & RRR & $95 \% \mathrm{CI}$ & RRR & $95 \% \mathrm{CI}$ \\
\hline \multicolumn{5}{|l|}{ Age (years) } \\
\hline - 40-49 & 1.00 & & 1.00 & \\
\hline$\cdot 50-59$ & 1.42 & $0.99-2.04$ & 1.30 & $0.81-2.10$ \\
\hline$\bullet \geq 60$ & 4.08 & $2.84-5.86$ & 1.81 & $1.10-2.96$ \\
\hline \multicolumn{5}{|l|}{ Marital status } \\
\hline - Single & 1.00 & & 1.00 & \\
\hline - Divorced/separated & 1.28 & $1.00-1.64$ & 1.72 & $1.14-2.60$ \\
\hline - Married & 1.28 & $1.00-1.64$ & 2.09 & $1.41-3.10$ \\
\hline \multicolumn{5}{|l|}{ Race/skin color } \\
\hline - Black & 1.00 & & 1.00 & \\
\hline - Brown (mixed) & 1.48 & 1.13-1.95 & 1.13 & $0.72-1.78$ \\
\hline - White & 1.59 & $1.23-2.07$ & 1.47 & $0.96-2.24$ \\
\hline - Asian & 1.43 & $0.89-2.30$ & 0.71 & $0.31-1.60$ \\
\hline - Indigenous & 1.01 & $0.43-2.37$ & 0.73 & $0.16-3.37$ \\
\hline \multicolumn{5}{|l|}{ Education } \\
\hline - High school or less & 1.00 & & 1.00 & \\
\hline - University education & 1.20 & $0.95-1.52$ & 1.66 & $1.14-2.40$ \\
\hline - Postgraduate degree & 1.04 & $0.84-1.28$ & 2.45 & $1.80-3.35$ \\
\hline \multicolumn{5}{|l|}{ Private health insurance } \\
\hline$\bullet$ No & 1.00 & & 1.00 & \\
\hline - Yes & 2.06 & $1.69-2.51$ & 2.86 & $2.00-4.09$ \\
\hline \multicolumn{5}{|l|}{ Self-rated health } \\
\hline - Very good/good & 1.00 & & 1.00 & \\
\hline - Fair/poor/very poor & 1.03 & $0.84-1.27$ & 0.93 & $0.66-1.32$ \\
\hline \multicolumn{5}{|l|}{ BMI } \\
\hline$\cdot \leq 24$ & 1.00 & & 1.00 & \\
\hline$\cdot 25-29$ & 1.13 & $0.94-1.37$ & 0.96 & $0.74-1.24$ \\
\hline$\cdot \geq 30$ & 0.64 & $0.51-0.79$ & 0.37 & $0.26-0.53$ \\
\hline \multicolumn{5}{|c|}{ Clinical contraindications to $\mathrm{HT}$ use $\mathrm{e}^{\dagger}$} \\
\hline • None & 1.00 & & 1.00 & \\
\hline - At least one & 0.90 & $0.72-1.12$ & 0.63 & $0.44-0.89$ \\
\hline
\end{tabular}

RRR, relative risk ratio; CI, confidence interval; BMI, body mass index; HT, hormone therapy.

Types in bold were used as a way to draw attention to values that reached statistical significance.

*Excluding women with premature ovarian failure, that is, primary and secondary amenorrhea due to radiotherapy, surgery, chemotherapy, or any condition resulting in menopause before age 40 years.

${ }^{\dagger}$ Triglyceride levels $>500 \mathrm{mg} / \mathrm{dl}$ and medical history of congestive heart failure, acute myocardial infarction, stroke, thromboembolism, systemic lupus erythematosus, breast cancer, endometrial cancer, liver cirrhosis, and hepatitis.

in patient care in the public sector also work in the private sector, ${ }^{39}$ and this dual role may promote what has been described as the "chameleon phenomenon," which is the adoption of different behaviors for each workplace and profile of clients. ${ }^{41} \mathrm{In}$ addition, despite the accumulation of evidence indicating limits related to age, to the duration of HT and to the time since menopause, the posture assumed by the specialist medical associations on the subject has been quite liberal, stressing the importance of clinical judgment, the cost-benefit ratio, and individualization. ${ }^{42,43}$ These aspects emphasize the subjective character of the prescription, leaving the decision in the hands of the doctor and the patient, based on their own individual beliefs, which are strongly influenced by advertising and the media. ${ }^{38,40}$ In a study conducted by the Brazilian Health Surveillance Agency (ANVISA), ${ }^{39} 64.9 \%$ of the physicians surveyed admitted to taking advertising information into consideration when choosing a product for prescription. It is worth noting that, as a rule, investigators participating in a consensus organized by a specialist medical association declare conflicts of interest and are often financed, to some extent, by the pharmaceutical companies that produce the hormones. It is impossible to be certain, however, whether this factor has any effect on the final text of the recommendations. ${ }^{13,43}$

Menopause, a normal life event, has been medicalized for many decades and treated under medical supervision and influence. The degree of medicalization of menopause varies from country to country and even from region to region within the same country. ${ }^{44,45}$ It cannot be ruled out that cultural aspects may contribute to these findings, because, in Brazil, the medicalization of female reproductive 
Table 3. Proportion of current use of systemic hormone therapy* by age and time since menopause, duration of use, and the presence of at least one clinical contraindication to its use, in women of 40-74 years of age who had undergone natural menopause. 'Brazilian Longitudinal Study of Adult Health baseline study, 2008-2010

\begin{tabular}{|c|c|c|c|}
\hline \multirow{3}{*}{ Selected characteristics } & \multicolumn{2}{|c|}{ Age (years) } & \multirow{3}{*}{$p$-value } \\
\hline & $40-59(n=196)$ & $\geq 60(n=112)$ & \\
\hline & $(\%)$ & $(\%)$ & \\
\hline Time of menopause (years) & & & 0.000 \\
\hline$\bullet<5$ & 53.6 & 4.6 & \\
\hline - 5-9 & 32.1 & 21.8 & \\
\hline$\bullet \geq 10$ & 14.3 & 73.6 & \\
\hline Duration of HT use (years) & & & 0.000 \\
\hline$\bullet<2$ & 30.8 & 9.1 & \\
\hline - $2-4$ & 33.8 & 11.8 & \\
\hline$\cdot \geq 5$ & 35.4 & 79.1 & \\
\hline Clinical contraindications to HT use & & & 0.196 \\
\hline - None & 89.8 & 84.8 & \\
\hline - At least one & 10.2 & 15.2 & \\
\hline
\end{tabular}

HT, hormone therapy.

*Excluding women in use of vaginal estrogen alone.

${ }^{\dagger}$ Excluding women with premature ovarian failure, that is, primary and secondary amenorrhea due to radiotherapy, surgery, chemotherapy, or any condition resulting in menopause before age 40 years.

${ }^{\ddagger}$ Triglyceride levels $>500 \mathrm{mg} / \mathrm{dl}$ and medical history of congestive heart failure, acute myocardial infarction, stroke, thromboembolism, systemic lupus erythematosus, breast cancer, endometrial cancer, liver cirrhosis, and hepatitis.

cycles has been represented as modern and social status enhancing, as highlighted by the example of the abusive cesarean section rate among more educated women with a higher income and private health insurance. ${ }^{46,47}$ In a previous study, women using HT had more contact with health services than those who had never used HT. ${ }^{48}$ One study showed that the frequency of ever use of HT by postmenopausal gynecologists was high prior to the WHI report $(71.4 \%)$, a fact that may have influenced prescription. ${ }^{49}$ After that, the vast majority of male and female specialists in this area admitted being aware of the WHI results (95.9\%), and although $84.6 \%$ stated that those results could not be extrapolated to forms of HT other than those evaluated in the study, a significant decrease in prescription was self-reported. ${ }^{50}$ Another finding of the ELSA-Brasil study was the inappropriate use of thyroxine by more educated women and those with higher incomes $^{51}$ and of benzodiazepines by those with health insurance, ${ }^{52}$ and this would appear to support this interpretation of the results and indicate the need for further studies on the quality of the private medical care often used by the more privileged socioeconomic classes in Brazil.

However, having at least one clinical contraindication to HT proved to be associated with less use. This finding suggests that most physicians consider the scientific evidence prior to reaching a decision on whether to prescribe HT, which has probably contributed to the historical decline in its use.
Body mass index $\geq 30$, another factor associated with less HT use, was also reported in a previous cohort study with currently employed women in France. ${ }^{34}$ The authors discussed two possible interpretations for this result: Thinner women would be less concerned about the side effects of HT, or they would have more menopausal symptoms because they produce less endogenous estrogen than those with a higher BMI. ${ }^{34}$ We cannot rule out the possibility that women with higher BMI (30+), who are at increased risk for these contraindications, were less likely to use HT for this reason.

Because this subpopulation of the ELSA-Brasil cohort consists of currently employed female volunteers, the results on the prevalence of HT use cannot be extrapolated to the entire population of Brazilian women or even to those in the cities where they were recruited. However, the greatest strength of our study is its longitudinal design and the fact that the women were followed up to monitor their use of HT and its effects on their health. Therefore, despite the limitations of the current cross-sectional analysis of these baseline data, these findings provide clues on which to base future longitudinal analyses to test hypotheses and clarify aspects that remain unclear.

These results from the largest study on the trends and patterns of HT use in Brazil will certainly contribute to the international debate. They may also subsidize national health policies and provide women with information to strengthen their participation in the decision-making process based on scientific evidence, 
giving them greater autonomy and protecting their physical integrity.

\section{ACKNOWLEDGEMENTS}

The ELSA-Brasil baseline study was supported by the Department of Science and Technology of the Brazilian Ministry of Health, the Brazilian Ministry of Science and Technology (financial resources for studies and projects), and the National Research Council/CNPq under grants $01060010.00 \mathrm{RS}, 01060212.00 \mathrm{BA}, 0106$ 0300.00 ES, 0106 0278.00 MG, $01060115.00 \mathrm{SP}$, and $01060071.00 \mathrm{RJ}$.

\section{CONFLICT OF INTEREST}

None declared. The supporting sources had no involvement in the study design, data collection, analysis, or interpretation, as well as in writing the report or in the decision to submit the report for publication.

\section{KEY POINTS}

- In the late 1990s, over half the women in the ELSA-Brasil cohort were using HT, a rate that is higher than those reported in most countries worldwide.

- From 1998 to 2007 and particularly in the first decade of the second millennium, the prevalence of HT use fell rapidly to $27.4 \%$, corresponding to a decrease of about $50 \%$.

- The use of HT remains more common among older, married, or divorced women, as well as in women with a better education level and in those with private health insurance, even after disclosure of the findings of the WHI study.

- $\mathrm{A} \quad \mathrm{BMI} \geq 30$ and having at least one clinical contraindication to the use of HT were found to be factors associated with less use.

- However, in the women of 60 years of age or more, an age group in which the risks outweigh the benefits, the absolute majority of HT users had been menopausal for at least 10 years and had been using HT for at least 5 years.

\section{ETHICS STATEMENT}

As a multicenter study, the ELSA-Brasil study protocol was submitted to and approved by the Brazilian National Ethics Council (CONEP), as well as by the internal review boards of all the participating institutes. This study in particular was approved by the internal review board of the Collective Health Institute, Federal University of Bahia.

\section{REFERENCES}

1. Hersh AL, Stefanick ML, Stafford RS. National use of postmenopausal hormone therapy: annual trends and response to recent evidence. JAMA 2004; 291(1): 47-53. doi:10.1001/jama.291.1.47

2. Collaborative Group on Hormonal Factors in Breast Cancer. Breast cancer and hormone replacement therapy: collaborative reanalysis of data from 51 epidemiological studies of 52,705 women with breast cancer and 108,411 women without breast cancer. Lancet 1997; 350(9084): 1047-1059. doi:10.1186/ bcr486.

3. Grady D, Herrington D, Bittner V, et al. Cardiovascular disease outcomes during 6.8 years of hormone therapy: Heart and Estrogen/Progestin Replacement Study follow-up (HERS II). JAMA 2002; 288(1): 49-57. doi:10.1001/jama.288.1.49.

4. Hulley S, Grady D, Bush T, et al. Randomized trial of estrogen plus progestin for secondary prevention of coronary heart disease in postmenopausal women. Heart and Estrogen/Progestin Replacement Study (HERS) research group. JAMA 1998; 280(7): 605-613. doi:10.1001/jama.280.7.605.

5. Rossouw JE, Anderson GL, Prentice RL, et al. Risks and benefits of estrogen plus progestin in healthy postmenopausal women: principal results from the Women's Health Initiative randomized controlled trial. JAMA 2002; 288(3): 321-333. doi:10.1001/jama.288.3.321.

6. Beral V. Breast cancer and hormone-replacement therapy in the Million Women Study. Lancet 2003; 362(9382): 419-427. doi:10.1016/S0140-6736(03)14065-2.

7. Faber A, Bouvy ML, Loskamp L, et al. Dramatic change in prescribing of hormone replacement therapy in the Netherlands after publication of the Million Women Study: a follow-up study. Br J Clin Pharmacol 2005; 60(6): 641-647. doi:10.1111/j.1365-2125.2005.02502.x.

8. Guay MP, Dragomir A, Pilon D, et al. Changes in pattern of use, clinical characteristics and persistence rate of hormone replacement therapy among postmenopausal women after the WHI publication. Pharmacoepidemiol Drug Saf 2007; 16(1): 17-27. doi:10.1002/pds.1273.

9. Ravdin PM, Cronin KA, Howlader N, et al. The decrease in breast-cancer incidence in 2003 in the United States. N Engl J Med 2007; 356(16): 1670-1674. doi:10.1056/NEJMsr070105.

10. The 2012 hormone therapy position statement of: the North American Menopause Society. Menopause 2012; 19(3): 257-271. DOI: $10.1097 /$ gme.0b013e31824b970a.

11. Stefanick ML. Estrogens and progestins: background and history, trends in use, and guidelines and regimens approved by the US Food and Drug Administration. Am J Med 2005; 118(Suppl 12B): 64-73. doi:10.1016/j. amjmed.2005.09.059.

12. Moyer VA. Menopausal hormone therapy for the primary prevention of chronic conditions: U.S. Preventive Services Task Force recommendation statement. Ann Intern Med 2013; 158(1): 47-54. doi:10.7326/0003-4819158-1-201301010-00553.

13. Santen RJ, Allred DC, Ardoin SP, et al. Postmenopausal hormone therapy: an Endocrine Society scientific statement. J Clin Endocrinol Metab 2010; 95 (7 Suppl 1): s1-s66. doi:10.1210/jc.2009-2509.

14. de Villiers TJ, Gass ML, Haines CJ, et al. Global consensus statement on menopausal hormone therapy. Maturitas 2013; 74(4): 391-392. doi:10.1016/j.maturitas.2013.02.001.

15. Pinto Neto AM, Pedro AO, Hardy E, et al. Caracterização das usuárias de terapia de reposição hormonal do Município de Campinas, São Paulo. Cad Saude Publica 2002; 18: 121-127. doi:10.1590/S0102-311X2002000100013.

16. Sclowitz IKT, Santos IS, Silveira MF. Prevalência e fatores associados a fogachos em mulheres climatéricas e pós-climatéricas. Cad Saude Publica 2005; 21: 469-481. doi:10.1590/S0102-311X2005000200013.

17. Aranha RN, Faerstein E, Azevedo GM, et al. Análise de correspondência para avaliação do perfil de mulheres na pós-menopausa e o uso da terapia de reposição hormonal. Cad Saude Publica 2004; 20: 100-108. doi:10.1590/S0102311 X2004000100024.

18. Oppermann K, Fuchs SC, Donato G, Bastos CA, et al. Physical, psychological, and menopause-related symptoms and minor psychiatric disorders in a community-based sample of Brazilian premenopausal, perimenopausal, and postmenopausal women. Menopause 2012; 19(3): 355-360. doi:10.1097/ gme.0b013e31822ba026.

19. Pedro AO, Pinto-Neto AM, Costa-Paiva LHS, et al. Síndrome do climatério: inquérito populacional domiciliar em Campinas, SP. Rev Saude Publica 2003; 37: 735-742. doi:10.1590/S0034-89102003000600008.

20. Zahar SEV, Aldrighi JM, Pinto Neto AM, et al. Qualidade de vida em usuárias e não usuárias de terapia de reposição hormonal. Rev Assoc Med Bras 2005; 51: 133-138. doi:10.1590/S0104-42302005000300012. 
21. Aquino EM, Barreto SM, Bensenor IM, et al. Brazilian Longitudinal Study of Adult Health (ELSA-Brasil): objectives and design. Am J Epidemiol 2012; 175(4): 315-324. doi:10.1093/aje/kwr294.

22. Beck-Peccoz P, Persani L. Premature ovarian failure. Orphanet J Rare Dis 2006; 1: 9. doi:10.1186/1750-1172-1-9.

23. World Health Organization Scientific Group. Research on the menopause in the 1990s. Geneva: WHO. Technical Report Series, 1996. 107p. Report No.: 866.

24. Lundberg V, Tolonen H, Stegmayr B, et al. Use of oral contraceptives and hormone replacement therapy in the WHO MONICA project. Maturitas 2004; 48(1): 39-49. doi:10.1016/j.maturitas.2003.08.006.

25. Barrett-Connor E, Espeland MA, Greendale GA, et al. Postmenopausal hormone use following a 3-year randomized clinical trial. J Womens Health Gend Based Med 2000; 9(6): 633-643. doi:10.1089/15246090050118161.

26. Connelly MT, Richardson M, Platt R. Prevalence and duration of postmenopausal hormone replacement therapy use in a managed care organization, 1990-1995. $J$ Gen Intern Med 2000; 15(8): 542-550. doi:10.1046/j.1525-1497.2000.03499.

27. Gravena AAF, Rocha SC, Romeiro TC, et al. Sintomas climatéricos e estado nutricional de mulheres na pós-menopausa usuárias e não usuárias de terapia hormonal. Rev Bras Ginecol Obstet 2013; 35: 178-184. doi:10.1590/S010072032013000400008.

28. Polisseni AF, Araújo DAC, Polisseni F, et al. Depressão e ansiedade em mulheres climatéricas: fatores associados. Rev Bras Ginecol Obstet 2009; 31: 28-34. doi:10.1590/S0100-72032009000100006.

29. Silva Filho CR, Baracat EC, Conterno LO, et al. Climacteric symptoms and quality of life: validity of women's health questionnaire. Rev Saude Publica 2005; 39: 333-339. doi:10.1590/S0034-89102005000300002.

30. Silva Filho EA, Costa AM. Avaliação da qualidade de vida de mulheres no climatério atendidas em hospital-escola na cidade do Recife, Brasil. Rev Bras Ginecol Obstet 2008; 30: 113-120. doi:10.1590/S0100-72032008005000001.

31. Silveira IL, Petronilo PA, Souza MO, et al. Prevalência de sintomas do climatério em mulheres dos meios rural e urbano no Rio Grande do Norte, Brasil. Rev Bras Ginecol Obstet 2007; 29: 415-422. doi:10.1590/S0100-72032007000800006.

32. Valadares AL, Pinto-Neto AM, Conde DM, et al. The opinion of women on menopause and treatment of its symptoms. Rev Assoc Med Bras 2008; 54(4): 299-304. doi:10.1590/S0104-42302008000400013.

33. Vigeta SMG, Brêtas ACP. A experiência da perimenopausa e pós-menopausa com mulheres que fazem uso ou não da terapia de reposição hormonal. Cad Saude Publica 2004; 20: 1682-1689. doi:10.1590/S0102-311X2004000600027.

34. Ringa V, Fritel X, Varnoux N, et al. Discontinuation of hormone therapy in the French GAZEL cohort 1990-2006. Fertil Steril 2010; 94(4): 1387-1391. doi:10.1016/j.fertnstert.2009.07.1001.

35. Paim J, Travassos C, Almeida C, et al. The Brazilian health system: history, advances, and challenges. The Lancet 2011; 377(9779): 1778-1797. doi:10.1016/ S0140-6736(11)60054-8.

36. Brasil. Ministério da Saúde, Secretaria de Ciência TeIE. DdAFeI, Estratégicos. Relação Nacional de Medicamentos Essenciais - Rename. Editora do Ministério da Saúde: Brasília, 2008; 142p.

37. Vieira FS. Assistência farmacêutica no sistema público de saúde no Brasil. Rev Panam Salud Publica 2010; 27(2): 149-156.

38. Mueller KA, Sanchez GJZ, Sievert LL. Sources of information and HRT prescribing practices among gynecologists in Puebla, México. Maturitas 2003; 45(2): 137-144. doi:10.1016/S0378-5122(03)00145-2.
39. Brasil. Agência Nacional de Vigilância Sanitária. Diagnóstico Situacional da Promoção de Medicamentos em Unidades de Saúde do Sistema Único de Saúde (SUS) / Agência Nacional de Vigilância Sanitária. ANVISA: Brasília, 2010; 85 p.

40. Rozenfeld S. Terapia hormonal para a menopausa (TH): múltiplos interesses a considerar. Cien Saude Colet 2007; 12: 437-442. doi:10.1590/S141381232007000200020 .

41. Santos IS, Baroni RC, Minotto I, et al. Critérios de escolha de postos de saúde para acompanhamento pré-natal em Pelotas. RS Rev Saude Publica 2000; 34(6): 603-609. doi:10.1590/S0034-89102000000600007.

42. Clapauch R, Athayde A, Meirelles RM, et al. Hormonal therapy of menopause: 2004 position of the Department of Female Endocrinology and Andrology of the Brazilian Society of Endocrinology and Metabolism. Arq Bras Endocrinol Metabol 2005; 49(3): 449-454. doi:10.1590/S000427302005000300018.

43. Wender MCO, de Melo PL, Fernandes CE. Consenso Brasileiro de Terapêutica Hormonal da Menopausa - Associação Brasileira de Climatério (SOBRAC). São Paulo: Leitura Médica, 2014; 148 p.

44. Bernis C, Reher DS. Environmental contexts of menopause in Spain: comparative results from recent research. Menopause 2007; 14(4): 777-787. doi:10.1097/ gme. $0 \mathrm{~b} 013 \mathrm{e} 31803020 \mathrm{ff}$.

45. Sievert LL, Saliba M, Reher D, et al. The medical management of menopause: a four-country comparison care in urban areas. Maturitas 2008; 59(1): 7-21. doi:10.1016/j.maturitas.2007.11.001.

46. Diniz SG. Gender. Maternal health and the perinatal paradox. Journal of Human Growth and Development 2009; 19 (Suppl 1_2): 313-326. Available at: <http:// www.revistas.usp.br/jhgd/article/view/19921>. Date accessed: 13 Aug. 2015. DOI: $10.1590 / \mathrm{S} 0104-12822009000200012$

47. Domingues RMSM, Dias MAB, Nakamura-Pereira M et al. Process of decisionmaking regarding the mode of birth in Brazil: from the initial preference of women to the final mode of birth. Cad de Saude Publica 2014; 30(Suppl 1): S101-S116. Available from: http://www.scielo.br/scielo.php?script=sci_arttext\&pid=S0102 $311 X 2014001300017 \& \operatorname{lng}=e n$. Date accessed: 20 Aug. 2015. DOI: 10.1590/ 0102-311X00105113.

48. Pedro AO, Pinto-Neto AM, Costa-Paiva L, et al. Procura de serviço médico por mulheres climatéricas brasileiras. Rev Saude Publica 2002; 36: 484-490. doi:10.1590/S0034-89102002000400015.

49. Pereira-Filho AS, Soares Junior JM, Arkader J, et al. Attitudes and practices about postmenopausal hormone therapy among female gynecologists in Brazil. Maturitas 2005; 51(2): 146-153. doi:10.1016/j.maturitas.2004.06.018.

50. Lazar F, Jr, Costa-Paiva L, Morais SS, Pedro AO, et al. The attitude of gynecologists in Sao Paulo, Brazil 3 years after the Women's Health Initiative study. Maturitas 2007; 56(2): 129-141. doi:10.1016/j.maturitas.2006.06.022.

51. Olmos RD, Figueiredo RC, Aquino EML, et al. Gender, race and socioeconomic influence on diagnosis and treatment of thyroid disorders in the Brazilian Longitudinal Study of Adult Health (ELSA-Brasil). Braz J Med Biol Res 2015; 48(8): 751-758. doi:10.1590/1414-431X20154445.

52. Brunoni AR, Nunes MA, Figueiredo $R$, et al. Patterns of benzodiazepine and antidepressant use among middle-aged adults. The Brazilian Longitudinal Study of Adult Health (ELSA-Brasil). J Affect Disord 2013; 151(1): 71-77. doi:10.1016/j.jad.2013.05.054 